\title{
Cultivating Ways on Intercultural Communicative Competence for English Teacher
}

\author{
Xiying Jiang \\ College of Foreign Languages, Bohai University, Jinzhou, 121013, China \\ jiangshan0030@126.com
}

\begin{abstract}
Keywords: English teacher; intercultural communicative competence; cultivating ways; influence factor; competence constitution
\end{abstract}

\begin{abstract}
Intercultural communicative competence training is an important task of English teaching, teachers' cross-cultural communication ability directly influences the training the students' ability of intercultural communication. Based on English teachers' intercultural communication ability could not meet the requirement of the era of quality education, the present situation of the study. With the influence factors of cross-cultural communication ability and English teachers' intercultural communication competence as the foundation, put forward the way to English teachers' intercultural communication ability. Specific include: expanding the global cultural knowledge enhance communication ability, and the combination of various training modes to improve the ability of cross-cultural communication, to strengthen the teaching of college English and the relationship between cross-cultural communication research, promoting the comprehensive cultural quality of English teachers, by nonverbal communication consciousness enhance the sensitivity to cross-cultural communication.
\end{abstract}

\section{Introduction}

Intercultural communication is a kind of communicative behavior, from the perspective of communication type, can be the interpersonal communication, also can is a communication between the people and the public. Brian Spitzberg individual thinks communication skills embodied in appropriate and effective communicative behavior in specific situations. In the context of intercultural communication, both parties have in common, differences, communication difficulty increases, the variables that affect effective communication include language differences, cultural differences, world outlook, values, etc. [1]. Kim came to a more specific definition of intercultural communication skills: ability to intercultural communicative is individual has the intrinsic ability, able to handle the key problems in cross-cultural communication, such as cultural differences, cultural strangeness, this cultural attitude within groups, and the resulting psychological pressure, etc.

Intercultural communicative competence training is an important task of English teaching, teachers' cross-cultural communication ability directly influences the training the students' ability of intercultural communication. For a long time, due to the competent department of education, schools and teachers' personal reasons, teachers' cross-cultural communication ability is not optimistic, cannot satisfy the requirement of the age of the quality-oriented education of English teachers. In spite of the language knowledge has reached a certain level, but also to the requirement of culture teaching from the ministry of education is far, can't meet the needs of the practice of cross-cultural communication. Through this article research is for the English teachers' intercultural communication ability training through various channels and diversified ways are put forward.

\section{Influence Factor on Intercultural Communicative Competence}

The influence factors of intercultural communicative competence are shown in Fig.1. Intellectual factor refers to the communicator with the degree of cultural understand, communication objects located in the more understand each other's culture, cross-cultural ability is stronger. The communicator should understand the purpose of cultural values and beliefs, understand the 
communication object from what cultural patterns, but should also master the target language culture and the verbal and nonverbal communication of the script; Emotional factors refers to the communicator communication object from different cultures and cross-cultural communicative behavior attitude, important characteristic is the anxiety to the cross-cultural communication activities, that is because of the ongoing or expectations of cross-cultural communication activities produce fear and anxiety mood; Mental factors. Mental factors are the embodiment of the knowledge and the emotion factor, the content including verbal and nonverbal expression, and role playing. Words refer to how individuals use the language. The communicator may know a lot of language knowledge of the target language, but the pragmatic competence is very poor, cannot use the target language in actual dialogue in fluent expression; Situation characteristic refers to the individual may be in a certain context showed strong ability of communication, and in the context of the other is not comfortable to deal with, so the size of the communicative competence in accordance with the context changes, affect the ability of the cross-cultural communication situation characteristics including environmental context, contact in advance, position difference and third-party interference, etc.

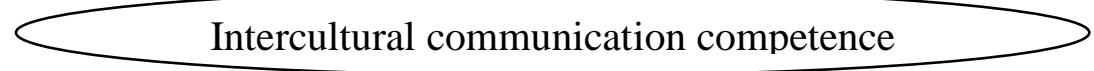

\begin{tabular}{|l|l|}
\hline $\begin{array}{l}\text { Emotional factors } \\
\text { - Avoid tendency } \\
\text { - Cross-cultural anxiety } \\
\text { - Communicative intention }\end{array}$ & $\begin{array}{l}\text { Mental activity factors } \\
\text { - Verbal performance } \\
\text { - Non-verbal performance } \\
\text { - Role playing }\end{array}$ \\
\cline { 2 - 2 } $\begin{array}{l}\text { Knowledge factors } \\
\text { - Cultural values, beliefs, and behaviors }\end{array}$ & $\begin{array}{l}\text { Situational characteristics } \\
\text { - Speech and speech script } \\
\text { - Cognitive simple and rigid } \\
\text { - National centralism }\end{array}$ \\
\hline
\end{tabular}

Fig. 1. Structure model on intercultural communication competence

\section{Constitution on Intercultural Communicative Competence for English Teacher}

English teachers' intercultural communicative competence includes six aspects, as shown in Fig. 2.

\begin{tabular}{|c|r|}
$\begin{array}{c}\text { Constitution on intercultural communicative } \\
\text { competence for English teacher }\end{array}$ \\
\hline English language competence & Social adaptation competence \\
\hline Intercultural communication competence & Self regulating competence \\
\hline
\end{tabular}

Fig. 2. Constitution on intercultural communicative competence for English teacher

(1) English language competence. The ability to use language based on language knowledge, language skills, emotional attitude, learning strategies and cultural awareness, etc. Use the English language communicative task, including set up and maintain social relations; Express personal emotions, feelings, thoughts and opinions; Reproducing life experience; Describes the world of the real or imagined; Specific task or action, etc.

(2) Communication expressing, and is an important part of communicative competence in communication skill, good communication is arranged orderly, his own thoughts and use it properly, 
make others understand you listen, but also deeply rooted in the hearts of the people. Competence refers to the form of verbal or nonverbal express their thoughts or feelings, so as to exchange ideas with people or emotional communication ability.

(3) Intercultural communication competence. Refer to the information, knowledge and the emotion passed each other, communication and understanding ability of those people from different cultural backgrounds. Grasp the different cultural knowledge and language tools, know more about their own culture and other cultural differences, it will improve the ability of intercultural communication.

(4) Environmental adaptation competence refers to people in order to survive in the society better by the psychological, physiological and behavioral change of various adaptive and society to achieve a harmonious state of a kind of executive ability to adapt. Personal life self-care ability, basic ability to work, choose some professions ability, social skills, using ethics discipline yourself, etc.

(5) Intercultural integration competence, cultural integration refers to the different characteristics of culture through the contact and communication between each other, and mutual absorption, permeability and study, integrated process. Intercultural fusion ability refers to the native culture and foreign culture mutual fusion and mutual adaptation ability.

(6) Self-regulating competence. The behavior is Self judgment after making rational behavior, the rational judgment and execution is self-control. Often is to realize the behavior to a lot of emotional control. Self-control is all made first through brain analysis, make clear judgment before dealing with the present situation.

\section{Cultivating Ways on Intercultural Communicative Competence for English Teacher}

After reviewing the relevant literature, through the example research, and the influence factors of cross-cultural communication ability and English teachers' intercultural communication competence as the basis, this paper summarizes the English teachers' intercultural communicative competence cultivation approaches as follows [4-7]:

(1) Expanded the global cultural knowledge enhance communication ability. Lack of cultural background knowledge cannot be set in a variety of behaviors of purpose in the context of specific national culture is appropriate and effective. Master and flexible use of national culture, makes English teachers easily across new value system that exist in the cross-cultural communication, religion and social behavior. While mastering related cultural knowledge cannot predict the ideas of purpose country behavior thoroughly, can provide guidance for teachers further depth fusion. Common way to broaden the cultural background of the channel has two kinds: one is to understand the purpose of the state in the multicultural communication object, context and discourse information such as the requirements of the people in general and decent behavior. These cultural communication object is English teachers aim to understand correctly the background of the basis of the verbal and nonverbal communication, is also the guidance of teachers of English to obtain appropriate communicative behavior. Secondly, cultivate communicative motivation, purpose of looking for opportunities to take an active part in the country's social communication activities. Through a variety of exotic culture activity, increase the exchange of experience and perceptual cognition of its culture.

(2) The combination of various training modes to improve intercultural communicative competence. Cross-cultural training is to improve employees' intercultural communication competence of conventional practice, also suitable for English teachers. Is now widely used include knowledge, cultural assimilation, self-consciousness, cultural awareness and simulation mode, etc. Each model has advantages and disadvantages, practical application of combined with the variety of pattern, exert advantages of combination. Knowledge model, to acquire knowledge by lectures and participate in class activities, the effect is limited to the cognitive layer and didn't extend to emotion, attitude and behavior level; Cultural assimilation model, provide students with a specific event of cross-cultural communication materials, students analyze how cultural differences and custom differences lead to conflict, and puts forward effective appropriate behavior in similar incidents; 
Self-awareness model, think people unless a good understanding of their native culture, otherwise can't understand his culture. Training focuses on students' emotion and feeling; Cultural awareness model, moving from understanding their own values to compared with other culture, eventually apply gain insights to improve interaction effect; Simulation mode, put students in the context of an analog communication, emphasizing emotional learning goals, specific cultural information and experience.

(3) Strengthen the research of the relationship between college English teaching and intercultural communication. Both mutual connection and restriction exist between language and culture. Culture has produced rich language, and produced the huge difference in language. These differences not only reflected in the language itself, but also embodied in the implicit semantics. Different language vocabularies is rich and colorful, it is caused by the unique cultural background. Inevitably involves culture, learning a language is more involved in intercultural communication, learning a language must study the corresponding culture at the same time. Foreign language teaching involves both native language and English language, language communicative competence training process inevitably involves the two cultures. English teaching not only teaches learners of English national culture, to master the language, customs, religion, manners, values and mode of production of knowledge, but also to convey the national culture through different forms of communication. Therefore he involves cross-cultural English teaching, but also restricted by cross-cultural. When learning a language, especially improve the ability of cross-cultural communication process, should fully absorb the western culture conducive to cultivate creative thinking, independent consciousness and innovative ideas to discover the potential of language learning.

(4) Improved English teachers' comprehensive cultural quality. Teachers' cultural literacy is a kind of comprehensive psychological characteristics, is an important part of teachers' professional quality, directly reflect the teacher's personality, temperament, values and outlook on life, etc. Due to the particularity of teachers, teacher's cultural quality should include three areas: the teacher's task is to spread culture, therefore must have established on the basis of common cultural knowledge of basic literacy; Teachers ought to be taught discipline experts, so must master taught discipline knowledge, and have to harness this discipline teaching discipline culture quality; Teachers cultivate people's work and must be familiar with the education of scientific knowledge must be and the idea embodied in their own education attitude and education of cultural quality. Study English in today's trend of society, English has become an indispensable part of people's life. Of intercultural communication, increasing puts forward more requirements on English teachers, teachers' cultural literacy plays a very important role in improving the teaching efficiency.

(5) By nonverbal communication consciousness to improve the sensitivity to intercultural communication. People's Daily lives by frequent social interactions, so the time needs to send or receive nonverbal communication. Nonverbal communication is the concept of social psychology, refers to people in conveying information, use the spoken and written languages of media, such as facial expressions, body language or tone auxiliary purpose. Through nonverbal communication, help to understand each other's mood, attitude and personal qualities, and even heart true intentions. Intercultural sensitivity is one part of the cross-cultural communication, and it is a person to inspire themselves understand, appreciate and accept the cultural differences of subjective will, intercultural sensitivity level directly influences the effect of cross-cultural communication. Through nonverbal communication seminar, understanding of nonverbal information symbols; through the life experiences, found Chinese and western different culture under the background of the differences of nonverbal behavior; Start from the details, pay attention to nonverbal communication information, gradually increase the sensitivity of the cross-cultural communication.

\section{Conclusion}

College English teachers are an important force in English education reform. Intercultural communicative ability is an important part of English teacher development, is also an important content of the evaluation of teachers. Change the current situation of English teaching and improve students' intercultural communicative competence, is a long-term and arduous task, the key is to 
teaching reform and enhancing teachers' intercultural consciousness. Education departments should fully realize the urgency of the problem, and formulate the corresponding feasibility measures to actively promote the reform and development of English teaching. To establish a high quality teachers, increase education investment, further intensify the English teacher training, comprehensive training of English teachers' intercultural consciousness and improve intercultural communication ability, constantly promote the all-round development of English teaching. In this paper, the research results, for the competent department of education to improve English teachers' intercultural communication ability training provide a theoretical basis and operability.

\section{References}

[1] D. T. Pan, "The connotation and composition of intercultural communicative competence," Journal of Hunan Padio and Febevision University, vol. 5, no. 4, pp. 92-93, 2005.

[2] L. Gao, F. Wang, "A tentative approach to intercultural communicative competence," Journal of Northwest University (Philosophy and Social Sciences Edition), vol. 37, no. 3, pp. 116-119, 2007.

[3] Baidu library, "Intercultural communicative competence," http://wenku.baidu.com/link?url=pr-uORfEpQMV8IXfk5OjvMHNZBLPFOJ9xpNGW8SL231 P3xXVtwOsyd1Rxmz29N6wICHgVFpixxW69Mj5VB1s11kUF00FLOs-5eE9RxLBosy, 2016-5-4.

[4] R. J. Hou, "On the cultivation of intercultural communicative competence of foreign language teachers in Colleges and Universities," Heilongjiang Researches on Higher Education, vol. 22, no. 6, pp. 74-75, 2003.

[5] L. Y. Dong, "A survey and research on English teachers' intercultural communication competence in the global promotion of Chinese language," Journal of Agricultural University of Hebei (Agriculture and Forestry Education Edition), vol. 14, no. 3, pp. 32-35, 2012.

[6] S. L. Guo, S. X. Ren, "Intercultural communication competence and intercultural training for college English teachers," Journal of Agricultural University of Hebei (Agriculture and Forestry Education Edition), vol. 15, no. 4, pp. 77-81, 2013.

[7] Q. Tai, "Approaches to the cultivation of intercultural communicative competence of College English teachers," Literature Education, vol. 10, no. 7, pp. 150, 2014. 